\title{
KINERJA GURU SENI BUDAYA MENDORONG KEWIRAUSAHAAN MANDIRI DI SEKOLAH MENENGAH KEJURUAN (SMK) SE KOTA MALANG
}

\author{
Muhammad 'Afaf Hasyimy', Yuyun Nur Astuti' ${ }^{2}$, Dewi Jasmine ${ }^{3}$, Robby Hidajat ${ }^{4}$ \\ Mahasiswa Program Studi Keguruan-Seni dan Desain Universitas Negeri Malang \\ Email: ${ }^{1}$ m.afafhasyimy.1902518@ @ students.um.ac.id, ${ }^{2}$ yuyunastuti.1902518@ @students.um.ac.id, \\ ${ }^{3}$ dewijasmine.1902518@students.um.ac.id, ${ }^{4}$ robby.hidajat.fs@um.ac.id
}

\begin{abstract}
This article examines the work of art and culture teachers applying entrepreneurship lessons in Vocational High Schools (SMK) throughout Malang, East Java. Entrepreneurship encourages student entrepreneurship from working in the industrial sector and government institutions. Receiving students to move industries that continue to improve The purpose of this study is to examine teacher performance Encouraging students to become entrepreneurs. This research method is descriptive quantitative. Data collection techniques through a questionnaire with Google Form on 11 art and culture teachers who are members of the Subject Teachers Association (MGMP) throughout Malang. Vocational Middle School (SMK) in Malang City is a school that is demanded from the implementation of entrepreneurship so that students have a great opportunity to utilize it as industrial technical personnel. The results showed more male teachers than female teachers, $54.5 \%$ male teachers, $45.5 \%$ educational background, as motivating students to produce applied art $81.8 \%$. While male teachers are able to encourage students to practice as sellers of school work in markets close to the school.
\end{abstract}

Key Words: Vocational High School, Entrepreneurship, Cultural Arts Teacher, Applied Arts

\begin{abstract}
Abstrak: Artikel ini mengkaji kerja guru seni budaya mengimplementasikan pelajaran kewirausahaan di Sekolah Menengah Kejuruan (SMK) se Kota Malang Jawa Timur. Kewirausahaan dimaksudkan mendorong peserta didik berwirausahawan dari pada kerja disektor industri dan instansi pemerintah. Mengingat peserta didik menghadapi industri yang terus mengalami peluktuatif. Tujuan penelitian ini mengkaji kinerja guru SMK mendorong peserta didik menjadi wirausahawan. Metode penelitian ini diskriptif kuantitatif. Teknik penjaringan data melalui angket dengan Google Forms pada 11 guru seni budaya anggota Musyawarah Guru Mata Pelajaran (MGMP) se-kota Malang. Sekolah Menegah Kejuruan (SMK) se Kota Malang merupakan sekolah yang dituntut menerapkan praktik kewirausahaan agar siswa mempunyai peluang besar bersaing dengan kemungkinan sebagai tenaga teknis industri. Hasil penelitian menunjukan guru laki-laki lebih dibanding guru wanita, jumlah guru laki-laki $54,5 \%$, latar belakang pendidikan $45,5 \%$, sebagai memotivasi siswa menghasilkan karya seni rupa terapan $81,8 \%$. Bahkan guru laki-laki mampu mendorong siswa mempraktikan sebagai penjual karya sekolah di pasar yang bedekatan dengan sekolah.
\end{abstract}

Kata kunci: Sekolah Menengah Kejuruan, Wirausaha, Guru Seni Budaya, Seni Rupa Terapan

\section{LATAR BELAKANG}

Pendidikan di Indonesia yang diterapkan pada Sekolah Menengah Kejuruan (SMK) terus didorong berkembang untuk mempersiapkan peserta didik mampu menghadapi perubahan ekonomi dunia (Hambali 2020). Hal tersebut dapat diperhatikan dari upaya sekolah mendorong untuk menerapkan program kewirausahaan (Farliana et al. 2015). Peran dari Pendidikan kejuruan di Indonesia melalui kurikulum 2013, yaitu mempersiapkan peserta didik menghadapi dunia industri (Sudana 2015). Sajauh itu 
pula, pada kenyataan di lapangan, persaingan kemampuan lulusan SMK semakin ketat (Perdana 2019). Upaya yang dilakukan oleh SMK di Malang Jawa Timur adalah menjalin kerjasama antara sekolah dan dunia industri melalui program magang (Sunarto and Supriadi 2019). Hal ini bertujuan agar lulusan pendidikan kejuruan bisa dan mampu memenuhi permintaan dari dunia industri (Wibowo 2016). Tetapi, pada kenyataannya hal tersebut belum sepenuhnya terwujud, karena lulusan SMK masih terkendala pengalaman penguasaan teknologi dan kematangan profesi (Pangastuti and Khafid 2019).

Elemen dan tujuan Pendidikan selalu dirumuskan melalui kurikulum, hal ini dapat diperhatikan melalui kurikulum 2013, yaitu melebukan nilai-nilai budaya dengan tuntutan ekonomi, sosial dan industri terkini (Hanjarwati and Aminah 2014). Kebutuhan sosial ekonomi selalu diperhatikan melalui pendidikan melalui kebijakan politik (Wiratma 2010). Kebijakan pendidikan ini secara makro juga ditujukan mengantisipasi pengaruh persaingan global. seseorang tenaga kerja harus mempunyai skilll yang berkualitas, sehingga dapat bersaing dengan negara lain (Fajar and Mulyanti 2019). Selain skilll yang berkualitas, para siswa juga dibekali dengan kemampuan adaptasi dalam mengembangkan bakat, minat, dan pengkondisian lingkungan yang kondosif pengembangan kewirausahaan (Putriatama, Patmanthara, and Sugandi 2016).

Tujuan penelitian ini mengkaji model kinerja guru SMK se Kota Malang dalam mendorong peserta didik menjadi wirausahawan mandiri. Mandiri yang diksud adalah mampu memproduksi produk bisnis. Hal ini didasarkan atas mata pelajaran seni budaya sub mata pelajaran seni rupa. Pada mata pelajaran tersebut mengimplementasikan kegiatan kreativitas dan inovasi, sehingga dalam memasuki dunia wirausaha tentunya sangat relefan. Namun sejauh itu pula hal tersebut akan berpulang pada kinerja guru bidang studi seni budaya yang bersangkutan. Oleh karena itu, penelitian ini dimungkinkan mengkaji upaya kinerja guru dengan berbagai aspek yang mempengaruhi, seperti jenis kelamin, latar belakang pendidikan, dan kondisi serta situasi sekolah masing-masing.

\section{TINJAUAN PUSTAKA}

Pendidikan kejuruan merupakan lembaga pendidikan yang mempersiapkan siswa agar mampu dibekali pengetahuan dan keterapilan untuk menghadapi era perkembangan industri dan teknologi (Rosul, 2013). Hal ini menuntut Pendidikan kejuruan merubah mindset sebagai sekolah yang menyiapkan tenaga kerja. Pendidikan dalam kejuruan membekali siswa dengan pendidikan dan pelatihan keterampilan. Pada era globalisasi ini pendidikan kejuruan menyiapkan peserta didik untuk memiliki daya adaptasi yang baik, memiliki komitmen perilaku yang baik, dapat hidup berdampingan secara mulkultural, dan memiliki jiwa kewirausahaan (Mardiyanti, 2015). Sebuah proses pembelajaran diharapkan mampu menumbuhkan potensi peserta didik agar memiliki adaptasi yang tinggi, berfikir fleksibel dan berfikir secara luas, serta mampu berfikir kreatif (Sani, 2013: 25).

Pembelajaran dalam Pendidikan kejuruan seharusnya membuat mata pelajaran yang ada mampu membuat siswa selalu berpikir kreatif (Irawan, 2015). Selain itu melalui pembelajaran dalam sebuah mata pelajaran di sekolah kejuruan diharapkan mampu mendorong siswa dalam semua bentuk mata pelajaran produktif ataupun pelajaran praktek yang menghasilkan produk menjadi sumber kewirausahaan. Dalam hal ini seorang pendidik pada setiap mata pelajaran merupakan tombak utama dalam hal itu 
(Wardhani, 2008: 35). Tak terkecuali mata pelajaran seni budaya. Pembelajaran seni budaya terdapat kompetensi empat bidang, yakni seni rupa, seni music, seni tari dan teater. Dalam seni rupa terdapat kompetensi seni rupa terapan nusantara yang mata pelajarannya mengarahkan peserta didik kepada seni rupa terapan yang ada di Indonesia. Didalamnya terdapat pembelajaran yang mengharuskan peserta didik memahami tentang seni rupa terapan nusantara, tidak hanya itu peserta didik juga diharapkan untuk mampu mendesain dan membuat seni rupa terapan khas daerahnya.

Artikel ini mengkaji kerja guru seni budaya yang mengimplementasikan pelajaran kewirausahaan pada mata pelajaran seni budaya di Sekolah Menengah Kejuruan (SMK) se-Kota Malang Jawa Timur. Kewirausahaan dimaksudkan mata pelajaran untuk menghadapi ketergantungan peserta didik pada sektor industri dan instansi pemerintah. Mengingat peserta didik menghadapi dunia industri yang terus mengalami peluktuatif.

Tujuan penelitian ini mengkaji model kinerja guru SMK mendorong peserta didik menjadi wirausahawan mandiri. Apakah pembelajaran di sekolah kejuruan yang mengharuskan para peserta didik mampu mempunyai skill sekaligus mental kuat untuk menghadapi perubahan ekonomi dunia dijadikan ajang untuk melatih para peserta didik terjun kedunia perdagaangan secara nyata lewat hasil/produk karyanya, dan menjadikan pasar lokal mengetahui akan kualitas produk tersebut, yang kemudian dapat menjadikan peserta didik secara nyata mengahadapi tantangan perekonomian dunia yang semakin pesat perkembangannya.

\section{METODE}

Penulisan penelitian ini menggunakan metode kuantitatif dengan prosentase hasil responden yang didiskripsikan dengan metode kualitatif. Pada pendekatan kualitatif tersebut peneliti menginterpretasi hasil responden dari guru-guru seni budaya se-kota Malang. Pengumpulan data menggunakan angket melalui google forms yang disebar melalui media sosial grup MGMP (Musyawarah Guru Mata Pelajaran) Seni Budaya SMK se-kota Malang dengan berbagai pertanyaan terkait dampak penerapan hasil karya seni terapan siswa. Pertanyaan yang ditanyakan pada reponden (1) apakah sekolah melaksanakan pembelajaran seni rupa terapan (2) apa produk seni rupa terapan yang dihasilkan (3) apakah produk seni rupa terapan dipamerkan (4)apakah produk seni rupa terapan dijual (5) kesulitan apa dalam menjual karya seni terapan yang dihasilkan siswa (6) apakah hasil karya siswa didisplay diruangan sekolah. Analisis yang digunakan dengan menggunakan prosentase dari jumlah responden dengan cara metabulasi hasil jawaban dengan diskriptif pada jawaban yang direspon oleh guru SMK se-kota Malang.

\section{PAPARAN DATA}

Pada aspek kurikulum pendidikan seni kompetensi yang diajarkan oleh guru pada siswa tersebut sesuai dengan kompetensi dasar mata pelajaran seni budaya untuk SMK yaitu pada kompetensi dasar 4.8. Mengekspresikan dengan menciptakan produk seni terapan dengan indicator siswa dapat memanfaatkan produk seni terapan tersebut. Sehingga tidak salah jika produk tersebut memiliki nilai fungsi-fungsi tertentu sesuai dengan indikator yang ingin dicapai oleh gurunya. Selain itu SMK lainnya memanfaatkan produk hasil karya seni siswa dengan digunakan sebagai hiasan pengisi ruangan.

Proses penelitian ini dilakukan dengan menggunakan data sumber dari berbagai guru-guru seni budaya di SMK se-kota Malang. Guru-guru tersebut 
tergabung pada Musyawarah Guru Mata Pelajaran berjumlah 11 orang. Responden tersebut dikondisikan melalu sosial media grop washap sebagai perwakilan guru matapelajaran yang diampu. Setiap responden diberikan pertanyaan yang tertujnuan untuk menggali identitas

Pertama peneliti membuat angket penelitian berupa beberapa pertanyaan yakni (1) Nama lengkap (2) Jenis kelamin (3) Umur (4) Asal sekolah (5) Sudah berapa lama anda mengajar (6) Apakah sekolah anda membuat produk seni rupa terapan (7) Bagaimana bentuk spembelajaran seni rupa terapan disekolah anda (8) Produk seni rupa terapan apa yang dihasilkan disekolah anda (9) Apakah produk tersebut dipamerkan (10) apakah produk seni rupa terapan tersebut dijual (11) Apakah lokasi sekolah berdekatan dengan pasar (12) Kesulitan apa yang didapatkan dalam menjual karya seni terapan tersebut (13) apakah seni rupa hasil karya siswa didisplay diruangan tertentu.

Kedua peneliti menyebarkan angket melalui grup media sosial whatsapp MGMP (musyawarah guru mata pelajaran) seni budaya dengan melalui link pada google form. Ketiga peneliti menganalisis hasil dengan memprosentase dengan metode kuantitatif untuk mendapatkan hasil dari penelitian Keempat menganalisis hasil prosentase kuantitatif tersebut dengan mengintepretasi jawaban dengan deskriptif kualitatif.

Peneliti mengkaji peluang kewirausahaan dalam mata pelajaran seni budaya, terutama pada seni rupa terapan. Hal ini memberikan dorongan peneliti untuk mengidentifikasi upaya guru seni budaya SMK se-kota Malang dalam mendorong kewirausahaan mandiri melalui hasil karya seni rupa terapan.

Selain itu untuk pembelajaran seni budaya di SMK lainnya memnafaatkan produk hasil seni terapannya dengan memanfaatkan sebagai hiasan ruangan seperti SMK Negeri 2 Malang membuat desain batik pada mata pelajaran seni budaya yang dihias di ruang guru, sedangkan SMK Negeri 8 Malang membuat kap lampu di hias pada ruangan studio seni budaya, SMK Negeri 9 Malang membuat batik jumputan digunakan sebagai hiasan pada ruang seni budaya, SMK Negeri 3 Malang membuat karya seni kolase yang digunakan sebagai hiasan pada bagian-bagian sekolah, SMK Negeri 11 membuat film animasi yang digunakan sebagai sumber belajar siswa, SMK Negeri 12 Malang membuat busana karnival digunakan sebagai parade yang diagendakan sekolah setiap kali kegiatan acara di sekolah, SMK Negeri 5 Malang membuat Tempat pensil, tudung saji, pigora, tempat kue, origami, bunga, vas bunga, celengan, miniature, robot, lampu, kipas angin, karya mozaik, baju, tas sabuk, alasan mereka tidak meniadakan penjualan terhadap produk dari anak-anak adalah ajang pameran yang bisa dimanfaatkan untuk media penjualan sekaligus promosi, selain itu tidak adanya koneksi untuk media promosi dan tempat penjualan menjadi faktor penghambat lain ditiadakannya penjualan, atau kurang berkualitasnya produk yang dihasilkan dan kurang mampu bersaing dengan pasar, ataupun terlalu tingginya harga produksi membuat mereka meniadakannya penjualan.

\section{ANALISIS DAN HASIL}

\section{Analisis Data}

Hasil pengumpulan data dari 11 guru SMK se Kota Malang, dan telah dilakukan pengecekan, serta tabulasi data. Langkah berikutnya dilakukan analisis berdasarkan berdasarkan diskripsi proesentase agar dapat diinterpertasikan

Tabulasi data dianalisis untuk setiap point pertanyaan dapat diperhatikan sebagai berikut. 
Tabel 1. Jumlah guru seni budaya laki-laki dan wanita

\begin{tabular}{|c|l|c|c|c|c|}
\hline $\begin{array}{c}\text { No } \\
\cdot\end{array}$ & \multicolumn{1}{|c|}{$\begin{array}{c}\text { Responde } \\
\mathrm{n}\end{array}$} & \multicolumn{2}{|c|}{$\begin{array}{c}\text { Laki-laki } \\
\text { (Jumlah } \\
\text { dan \%) }\end{array}$} & \multicolumn{2}{|c|}{$\begin{array}{c}\text { Wanita } \\
\text { (Jumlah } \\
\text { dan \%) }\end{array}$} \\
\hline 1. & $\begin{array}{l}11 \text { Guru } \\
\text { Seni } \\
\text { budaya }\end{array}$ & 6 & $\begin{array}{c}54.5 \\
\%\end{array}$ & 5 & $\begin{array}{c}45.5 \\
\%\end{array}$ \\
\hline
\end{tabular}

Tabel jumlah guru seni budaya di kota Malang seperti pada tabel di atas menunjukan perbedaan antara guru lakilaki dan guru wanita. Hasilnya tidak menunjukan perbedaan yang signifikan. Hanya menunjukan selisih satu orang guru laki-laki.

Tabel 2. Rentang usia guru seni budaya laki-laki dan wanita

\begin{tabular}{|l|l|c|c|c|c|}
\hline No. & $\begin{array}{l}\text { Rentang } \\
\text { usia }\end{array}$ & \multicolumn{2}{|c|}{$\begin{array}{c}\text { Laki-laki } \\
\text { (Jumlah dan } \\
\%)\end{array}$} & \multicolumn{2}{|c|}{$\begin{array}{c}\text { Wanita } \\
\text { (Jumlah } \\
\text { dan \%) }\end{array}$} \\
\hline 1 & $\begin{array}{l}\text { Usia 23- } \\
25 \text { tahun }\end{array}$ & 0 & $0 \%$ & 1 & $9.1 \%$ \\
\hline 2 & $\begin{array}{l}\text { Usia 26- } \\
30 \text { tahun }\end{array}$ & 0 & $0 \%$ & 1 & $9.1 \%$ \\
\hline 3 & $\begin{array}{l}\text { Usia di } \\
\text { atas 30 } \\
\text { tahun }\end{array}$ & 6 & $54.5 \%$ & 3 & $27.3 \%$ \\
\hline
\end{tabular}

Tabel rentang usia guru seni budaya di kota Malang terlihat kurang seimbang untuk tenaga pengajar yang memiliki rentang usia muda dan usia di atas 30 tahun, untuk guru yang umurnya dibawah 30 tahun hanya terdapat 2 guru. Guru yang berusia di atas 30 tahun menunjukan perbedaan yang $50 \%$ lebih banyak guru laki-laki di bandingkan guru wanita.

Tabel 3. Lulusan pendidikan terakhir guru seni budaya

\begin{tabular}{|l|l|c|c|c|c|}
\hline No. & \multicolumn{1}{|c|}{ Pendidikan } & \multicolumn{2}{|c|}{$\begin{array}{c}\text { Laki-laki } \\
\text { (Jumlah } \\
\text { dan \%) }\end{array}$} & \multicolumn{2}{|c|}{$\begin{array}{c}\text { Wanita } \\
\text { (Jumlah } \\
\text { dan \%) }\end{array}$} \\
\hline 1 & S1 Kesenirupaan & 5 & $45.5 \%$ & 3 & $27.2 \%$ \\
\hline 2. & S1 Non Kesenirupaan & 1 & $9.1 \%$ & 0 & $0 \%$ \\
\hline
\end{tabular}

\begin{tabular}{|l|l|l|l|l|l|}
\hline 3. & S2 Kesenirupaan & 1 & $9.1 \%$ & 1 & $9.1 \%$ \\
\hline
\end{tabular}

Tabel di atas menunjukkan adanya perbedaan yang sangat berbeda ditinjau dari lulusan pendidik seni budaya, lulusan S1 untuk bidang kesenirupaan di bandingkan dengan lulusan S2 kesenirupaan, sedangkan untuk lulusan non kesenirupaan hanya 1 guru. Lulusan yang berasal dari bidang studi kesenirupaan untuk laki-laki berjumlah 5 orang, dan untuk guru wanita berjumlah 3 orang. Hal ini menunjukan masih lebih banyak guru laki-laki yang memiliki latar belakang bidang akademik kesenirupaan.

Tabel 4. Rentang waktu pengabdian guru seni budaya mengajar

\begin{tabular}{|c|c|c|c|c|c|}
\hline $\begin{array}{c}\text { No } \\
\cdot\end{array}$ & $\begin{array}{c}\text { Lama } \\
\text { pengabdia } \\
\mathrm{n}\end{array}$ & \multicolumn{2}{|c|}{$\begin{array}{c}\text { Laki-laki } \\
\text { (Jumlah } \\
\text { dan \%) }\end{array}$} & \multicolumn{2}{|c|}{$\begin{array}{c}\text { Wanita } \\
\text { (Jumlah } \\
\text { dan \%) }\end{array}$} \\
\hline 1 & $1-5$ tahun & 0 & $0 \%$ & 1 & $9 \%$ \\
\hline 3 & $\begin{array}{l}\text { Lebih dari } \\
5 \text { tahun }\end{array}$ & 6 & $\begin{array}{c}54.5 \\
\%\end{array}$ & 4 & $\begin{array}{c}36.5 \\
\%\end{array}$ \\
\hline
\end{tabular}

Tabel rentang waktu pengabdian guru seni budaya di sekolah masingmasing. Dapat diperhatikan, bahwa ada perbedaan antara guru laki-laki dan wanita. Rentang pengabdian guru seni budaya lebih dari lima tahun tampak lebih banyak guru laki-laki pada guru wanita.

Tabel 5. Penerapan kewirausahaan melalui seni budaya

\begin{tabular}{|c|l|c|c|c|c|}
\hline $\begin{array}{c}\text { No } \\
\cdot\end{array}$ & $\begin{array}{l}\text { Program seni } \\
\text { budaya }\end{array}$ & \multicolumn{2}{|c|}{$\begin{array}{c}\text { Ya } \\
\text { (Jumlah } \\
\text { dan \%) }\end{array}$} & \multicolumn{2}{|c|}{$\begin{array}{c}\text { Tidak } \\
\text { (Jumlah } \\
\text { dan \%) }\end{array}$} \\
\hline 1 & $\begin{array}{l}\text { Kewirausaha } \\
\text { an melalui } \\
\text { mata } \\
\text { pelajaran } \\
\text { seni budaya }\end{array}$ & 2 & $\begin{array}{c}18.2 \\
\%\end{array}$ & 9 & $\begin{array}{c}81.8 \\
\%\end{array}$ \\
\hline
\end{tabular}

Tabel guru yang penerapan kewirausahaan memiliki perbedaan yang sangat tajam, yaitu, dari 11 guru seni budaya di SMK se Kota Malang ditemukan hanya 2 orang guru yang menerapkan 
praktik kewirausahaan. Sementara 9 orang guru seni budaya memilih tidak menerapkan praktik kewirausahaan.

Tabel 6. Hasil seni terapan yang dihasilkan

\begin{tabular}{|l|l|l|l|l|l|}
\hline No. & $\begin{array}{l}\text { Produksi } \\
\text { hasil seni } \\
\text { terapan }\end{array}$ & \multicolumn{2}{|c|}{$\begin{array}{c}\text { Ya } \\
\text { (Jumlah } \\
\text { dan \%) }\end{array}$} & \multicolumn{2}{|c|}{$\begin{array}{l}\text { Tidak } \\
\text { (Jumlah } \\
\text { dan \%) }\end{array}$} \\
\hline 1 & $\begin{array}{l}\text { Blangkon, } \\
\text { batik, kap } \\
\text { lampu, } \\
\text { busana } \\
\text { karnaval, } \\
\text { baju, dan } \\
\text { aneka } \\
\text { gerabah }\end{array}$ & $81.8 \%$ & 2 & $18.2 \%$ \\
\hline
\end{tabular}

Tabel hasil produk hasil belajar yang memiliki potensi untuk dibisniskan. Pada tabel 6 dapat diperhatikan ada 9 responden yang memproduksi beraneka macam prodauk komersial. Sementara hanya 2 guru yang tidak menghasilkan produk.

Tabel 7. Hasil dari berkarya seni terapan yang diterapkan pada kewirausahaan

\begin{tabular}{|c|c|c|c|c|c|}
\hline No & $\begin{array}{c}\text { Praktek } \\
\text { kewirausaha } \\
\text { an }\end{array}$ & \multicolumn{2}{|c|}{$\begin{array}{c}\mathrm{Ya} \\
\text { (Jumlah } \\
\text { dan \%) }\end{array}$} & \multicolumn{2}{|c|}{$\begin{array}{c}\text { Tidak } \\
\text { (Jumlah } \\
\text { dan \%) }\end{array}$} \\
\hline 1 & $\begin{array}{l}\text { Produk } \\
\text { dijual }\end{array}$ & 2 & $\begin{array}{c}18.2 \\
\%\end{array}$ & 9 & $\begin{array}{c}81.8 \\
\%\end{array}$ \\
\hline 2 & $\begin{array}{l}\text { Produk } \\
\text { dipamerkan }\end{array}$ & 8 & $\begin{array}{c}72.8 \\
\%\end{array}$ & 3 & $\begin{array}{c}27.2 \\
\%\end{array}$ \\
\hline 3 & $\begin{array}{l}\text { Produk } \\
\text { hanya dihias } \\
\text { di sekolah }\end{array}$ & 6 & $\begin{array}{c}54.5 \\
\%\end{array}$ & 5 & $\begin{array}{c}45.5 \\
\%\end{array}$ \\
\hline
\end{tabular}

Pada tabel 7 dapat disimak, bahwa hasil karya seni rupa terapan dengan variasinya. Hal ini menunjukan bahwa hanya ada 2 responden yang menjual produk karya hasil belajar, sementara 8 responden memilih produk karya seni trapan sebagai bahan yang dipamarkan, dan 6 responden menyatakan karya seni terapan hanya dikoleksi untuk hiasan sekolah.
Tabel 8. Hasil berkarya seni terapan yang diterapkan pada kewirausahaan

\begin{tabular}{|l|l|l|l|l|l|}
\hline No. & Jenis Pasar & \multicolumn{2}{|c|}{$\begin{array}{l}\text { Ya } \\
\text { (Jumlah } \\
\text { dan \%) }\end{array}$} & \multicolumn{2}{|c|}{$\begin{array}{l}\text { Tidak } \\
\text { (Jumlah } \\
\text { dan \%) }\end{array}$} \\
\hline 1 & $\begin{array}{l}\text { Berdekatan } \\
\text { dengan } \\
\text { pasar }\end{array}$ & 3 & $27.2 \%$ & 8 & $72.8 \%$ \\
\hline
\end{tabular}

Tabel di atas menunjukan adanya perbedaan lokasi sekolah. Pertanyaan ini dimungkinkan ada faktor eksternal yang mungkin memberikan pengaruh besar terhadap minat guru untuk menerapkan kewirausahaan. Berdasarkan responden, bahwa ada 3 responden menyatakan, bahwa letak sekolah yang berdekatan dengan pasar ada 3 . Sementara 8 responden menyatakan letak sekolahnya berjauhan dengan pasar.

\section{Hasil Penelitian}

Dari hasil paparan data di atas dapat ditarik kesimpulan bahwa prosentase data yang dominan ditunjukan dari kecenderungan guru-guru SMK se Kota Malang yang mendorong kinerja kewirausahaan pada siswanya. Pada paparan data ditunjukan sebagai berikut guru laki-laki (6 orang atau 54,5\%), guru laki-laki juga menunjukan usia lebih dari 30 tahun (6 orang atau 54,5\%). Guru lakilaki yang memiliki latar belakang akademik kesenirupaan juga lebih dominan dari wanita (5 orang atau 45,6\%), laki-laki juga mempunyai pengabdian yang lebih lama dibanding dengan guru wanita (6 orang atau $54,5 \%$ ).

Data tersebut di atas menunjukan, bahwa guru laki-laki lebih dominan di SMK se Kota Malang. Namun hasil data yang mendorong siswa medapat memperloleh pengetahuan dan pengalaman sebagai wirausaha ternyata menunjukan, bahwa dari 11 guru seni budaya di SMK se Kota Malang hanya ada 2 guru atau 18,2\%. Namun jika 
diperhatikan lebih lanjut, pelajaran yang menghasilkan seni rupa terapan dilakukan oleh 9 guru atau 81,8\%. Hal ini tampak adanya selisih yang tidak signivikan, bahwa produk yang dihasilkan oleh siswa SMK se Kota Malang hanya didorong dari segi potensial dengan tidak diimbangi oleh guru yang melakukan praktik kewirausahaan, yaitu hanya 2 orang, perhatikan pada tabel 7 , produk yang dijual.

Temuan tersebut di atas dilakukan analisis yang lebih mendalam, yaitu memperhatikan faktor eskternal. Peneliti berusaha untuk meluaskan data dengan memperhatikan faktor kedekatan sekolah dengan pasar. Ternyata semua SMK yang ada di Kota Malang hanya ada 3 sekolah yang berdekatan dengan pasar. Terhatikan tabel 8 .

Jika diperhatikan, paparan data dan hasil analisis menunjukan adanya kecendrungan guru laki-laki memiliki peluang lebih besar mendorong siswa untuk melakukan praktik berkarya seni rupa terapan yang bernilai ekonomis, mendorong praktik kewirausahaan, dan adanya kedekatan sekolah dengan pasar.

\section{KESIMPULAN}

Sekolah Menegah Kejuruan (SMK) se Kota Malang merupakan sekolah yang dituntut menerapkan praktik kewirausahaan agar siswa mempunyai peluang besar bersaing dengan kemungkinan sebagai tenaga teknis industri. Hasil penelitian menunjukan, bahwa guru laki-laki dimungkinkan lebih besar menjadi motor pengerak memotivasi siswa pada mata pelajaran seni budaya menghasilkan karya seni rupa terapan. Bahkan guru laki-laki dimungkinkan juga mampu mendorong siswa memraktikan kegiatan kewirausahaan dengan cara menjual produk di pasar yang bedekatan dengan sekolah.

\section{DAFTAR RUJUKAN}

Fajar, Catur Martian, and Dwinta Mulyanti. 2019. "Meningkatkan Taraf Perekonomian Dan Kesejahteraan Melalui Perencanaan Investasi Pendidikan." Jurnal Abdimas BSI: Jurnal Pengabdian Kepada Masyarakat 2(1).

Farliana, Nina, Nina, Farliana, Nina, Farliana, and Nina. 2015. "Kontekstual Pengembangan Bahan Ajar Kewirausahaan SMK / Nina Farliana." SKRIPSI Mahasiswa UM 0(0).

Hambali, IM. 2020. "Prospek Karir Lulusan Sekolah Menengah Kejuruan: Content Audit Terhadap Kurikulum Dan Tema Layanan Konseling." Cendekia: Jurnal Pendidikan Dan Pembelajaran 14(1):13-26.

Hanjarwati, Astri, and Siti Aminah. 2014. "Evaluasi Implementasi Kebijakan Pemerintah Kota Yogyakarta Mengenai Pendidikan Inklusi." INKLUSI 1(2):221.

Pangastuti, Uswatun, and Muhammad Khafid. 2019. "Peran Kematangan Karir Dalam Memediasi Kompetensi Kejuruan Dan Efikasi Diri Terhadap Kesiapan Kerja Siswa." Economic Education Analysis Journal 8(2):485-500.

Perdana, Novrian Satria. 2019. "ANALISIS PERMINTAAN DAN PENAWARAN LULUSAN SMK DALAM PEMENUHAN PASAR TENAGA KERJA." Refleksi Edukatika : Jurnal Ilmiah Kependidikan 9(2).

Putriatama, Ega, Syaad Patmanthara, and R. .. Sugandi. 2016. "KONTRIBUSI PENGALAMAN PRAKERIN, WAWASAN DUNIA KERJA DAN KOMPETENSI KEJURUAN MELALUI EMPLOYABILITY SKILL SERTA DAMPAKNYA TERHADAP KESIAPAN KERJA LULUSAN SMK KOMPETENSI KEAHLIAN TEKNIK KOMPUTER DAN JARINGAN DI PROBOLINGGO." Jurnal Pendidikan: Teori, Penelitian, Dan Pengembangan 
Muhammad 'Afaf Hasyimy, Yuyun Nur Astuti, Dewi Jasmine, Robby Hidajat

KINERJA GURU SENI BUDAYA MENDORONG KEWIRAUSAHAAN MANDIRI

DI SEKOLAH MENENGAH KEJURUAN (SMK) SE KOTA MALANG

$1(8): 1544-54$.

Sudana, I. Wayan. 2015. LAPORAN AKHIR

PENELITIAN STRATEGIS NASIONAL

PENGEMBANGAN KERAJINAN

KERAMIK GERABAH TRADISIONAL

GORONTALO MELALUI KREASI

DESAIN BARU DAN PERBAIKAN

PROSES PRODUKSI UNTUK

MENDUKUNG INDUSTRI KREATIF.

Vol. 2.

Sunarto, Sunarto, and Didi Supriadi. 2019.

"Efektivitas Implementasi Model

Pembelajaran SMK Dalam Memenuhi

Tantangan Revolusi Industri 4.0."

TAMAN VOKASI 7(2):190.

Wibowo, Nugroho. 2016. "Upaya

Memperkecil Kesenjangan Kompetensi

Lulusan Sekolah Menengah Kejuruan

Dengan Tuntutan Dunia Industri."

Jurnal Pendidikan Teknologi Dan

Kejuruan 23(1):45.

Wiratma, I. Gusti Lanang. 2010. “POLITIK

PENDIDIKAN DALAM

PENGEMBANGAN KESADARAN

KRITIS DAN JATI DIRI." Jurnal IKA

$8(2)$. 